\title{
Design and demonstration in vitro of mouse-specific Transcranial Magnetic Stimulation coil
}

\section{Farah A. Khokhar ${ }^{1}$, Logan J. Voss ${ }^{2}$, D. Alistair Steyn-Ross ${ }^{3}$ and Marcus T. Wilson ${ }^{1}$}

1. School of Science, University of Waikato, Private Bag 3105, Hamilton 3240, New Zealand

2. Anaesthesia Department, Waikato District Health Board, Pembroke Street, Private Bag 3200, Hamilton 3240, New Zealand

3. School of Engineering, University of Waikato, Private Bag 3105, Hamilton 3240, New Zealand

\section{Abstract \\ Background}

Transcranial Magnetic Stimulation (TMS) is a technique used to treat different neurological disorders non-invasively. A pulsed current to a coil induces an $E$-field. Underlying biophysical effects of TMS are unclear. Therefore, animal experiments are needed; however, making small TMS coils suitable for mice is difficult because their field strengths are much lower than for human sized coils.

\section{Objectives/Hypothesis}

We aimed to design and demonstrate a mouse-specific coil that can generate high and focused $E$-field.

\section{Methods}

We designed a tapered TMS coil of 50 turns of $0.2 \mathrm{~mm}$ diameter copper wire around a $5 \mathrm{~mm}$ diameter tapered powdered iron core and discharged a $220 \mu \mathrm{F}$ capacitor at $50 \mathrm{~V}$ through it. We measured $B$-field with a Hall probe and induced $E$-field with a wire loop. We measured temperature rise with a thermocouple. We applied 1200 pulses of cTBS and iTBS to mouse brain slices and analysed how spontaneous electrical activity changed. 


\section{Results}

The coil gave maximum $B$-field of $760 \mathrm{mT}$ and maximum E-field of $32 \mathrm{~V} / \mathrm{m}, 2 \mathrm{~mm}$ below the coil, at $50 \mathrm{~V}$ power supply with a temperature increase of 20 degrees after 1200 pulses of cTBS. cTBS reduced frequency of spontaneous activity up to 20 minutes after stimulation and iTBS increased frequency of up to 20 minutes after stimulation. No frequency changes occurred after 20 minutes. No frequency changes in amplitude of spontaneous events were found.

\section{Conclusion}

The design generated focused fields strong enough to modulate brain activity in vitro.

\section{Introduction}

Transcranial Magnetic Stimulation is a non-invasive medical technique $(1,2)$ used in treatment of major depression (3-5) and therapeutically tested for epilepsy (6), stroke (2), Parkinson's disease (7), functional hand dystonia (8-10) and Alzheimer's disease (11-14). During TMS, a large pulse of current of less than 1 millisecond (ms) duration passes through a TMS coil placed on human head. This current pulse produces a changing magnetic field which in turn induces an electric field within the brain (15-19). While the physics of the coil is well-understood, the fundamental neurophysiological effects of the induced electric field, such as TMS-induced plasticity (20-22), changes in cortical excitability (20,23-26) and TMS-induced neuronal effects (27), are not clear. There is a need to perform invasive measurements to obtain a profound understanding of the underlying principles of TMS (24-33). Therefore, animal experiments are needed to obtain a better understanding behind the mechanisms of TMSinduced plasticity and changes in excitability. Mice are particularly suitable for invasive experiments because their brain geometry and connections have been well mapped (34).

Classic figure-of-eight human TMS coils, around $60-70 \mathrm{~mm}$ diameter $(35,36)$, with magnetic field strength of $1.5-2.5 \mathrm{~T}(15,36-38)$ and induced electric field strength of $150-250 \mathrm{~V} / \mathrm{m}$ (39) are designed to stimulate a small and focused area of human cortex. Applied to a mouse, the human TMS coil would stimulate the entire mouse brain. Therefore, a miniaturized coil is required that could mimic the electromagnetic field strengths of a human TMS coil $(18,19,28$, 35). The mouse-specific TMS coil should be designed in terms of the size difference of human and mouse brain. Broadly, the mouse brain is smaller than the human brain by a factor of approximately 10 in linear dimensions (40). Additionally, the surface of the mouse brain lies approximately $2 \mathrm{~mm}$ below the skin surface at the top of the head (41) compared to human 
brain which is around $20 \mathrm{~mm}$ below from the surface (42). Therefore, one would expect an appropriate mouse coil to be of order $6-7 \mathrm{~mm}$ in size. There are several physical and technical challenges in scaling down to small-scale TMS coils. For example, applying large currents will lead to overheating $(19,28,43,44)$. Furthermore, there is a lack of clarity on what parameters should be optimised in a small-scale coil design $(19,45)$. Options could include greater stimulation focality by offsetting coil position $(46,47)$, improving stimulation focality by scaling down human TMS coils (48), or achieving high magnetic field intensities by reducing the coil size (49). In general, there is a trade-off between greater electric field intensity and loss of focality (50), which makes design of mouse coils particularly challenging.

The magnetic and electric field strengths do not scale with size in the same way, thus optimizing both magnetic field and electric field simultaneously may be unachievable (19). To scale the magnetic field intensity requires only one-tenth current in a tenth-size coil to match the intensity of a human TMS coil, whereas to match the electric field intensity requires the same amount of current as in human coils, which is likely to create hazardous levels of Joule heating $(1,51)$.

There has been some previous work on small coil design. Tang et al. constructed an iron-core rodent-specific TMS coil having $8 \mathrm{~mm}$ outer diameter by winding 780 turns of insulated copper wire that delivered the magnetic field strength of approximately $120 \mathrm{mT}$ and an induced electric field strength modelled at around $12.7 \mathrm{~V} / \mathrm{m}$ on the surface of a rat cortex at $100 \mathrm{~V}$ power supply (28). Wilson et al. have designed and constructed a $5 \mathrm{~mm}$ mouse-specific ferrite core coil. The ferrite eliminated eddy currents that were present in the Tang et al. core (28). Windings were reduced to 70 turns to reduce inductance. The coil demonstrated a magnetic field strength of around $180 \mathrm{mT}$, at a depth below $2 \mathrm{~mm}$ below the coil, the induced electric field was estimated at around $2.5 \mathrm{~V} / \mathrm{m}$ in air for a $30 \mathrm{~V}$ power supply (19). Minusa et al. used an implantable set of magnetic stimulators to apply magnetic stimulation directly to the brain surface of mice. Coils were $1 \mathrm{~mm}$ long and $0.5 \mathrm{~mm}$ diameter and provided a highly-focused $B$-field of around $5 \mathrm{mT}$ (52). Despite this recent progress, these fields remain much lower than the fields of equivalent human TMS coils (53).

In this work, we have designed a mouse-specific coil with increased field strengths. To demonstrate its effect, we have applied 1200 pulses of continuous theta-burst stimulation (cTBS) and intermittent theta-burst stimulation (iTBS) (54) to mouse brain slices in vitro. Theta-burst stimulation consists of application of short bursts of pulses (usually 3 pulses in a 
burst, $20 \mathrm{~ms}$ apart, with 5 bursts per second) and is often used to investigate plasticity and excitability mechanisms within the brain. In cTBS experiments, we have applied bursts continuously for 80 seconds, whereas in iTBS experiments we have repeated 2 seconds of stimulation followed by an 8 second pauses for 400 seconds.

We have used spontaneous electrical activity in the cortex, measured through the local field potential, as a simple measure of the impact of stimulation. Specifically, we measure the amplitude and rate of 'seizure-like events' (SLEs), or spontaneous epileptiform-like activity as shown in Figure 1, due to correlated firing of groups of neurons in a slice that is prepared in an artificial cerebrospinal fluid from which magnesium ions have been removed (55). While the method does not provide subtle detail about any mechanisms of TMS interaction with the brain, it does serve to allow a simple demonstration that the field strengths are sufficient for changes in the brain to occur as a result of stimulation.

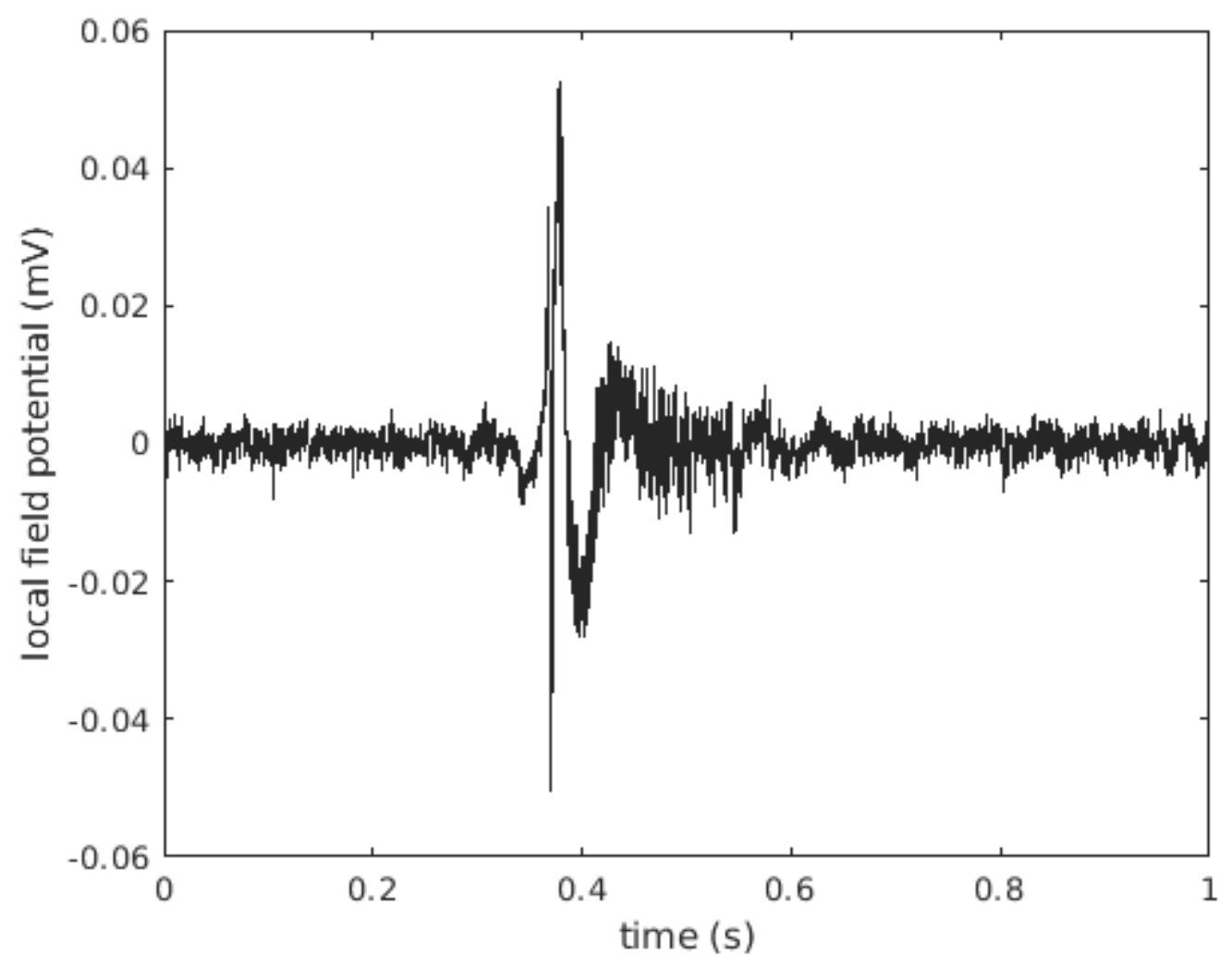

Figure 1: Typical example of an expanded view of a single no-magnesium seizure-like event.

We begin by describing the coil design. We then give details of the methodology for measuring the coil performance in terms of field strengths and spatial distribution, and the effect on SLEs 
in vitro. Finally, we present the results and discuss implications for use of TMS coils for mice and suggest future coil designs.

\section{Methods}

\subsection{Coil design}

We have constructed a mouse-specific coil by winding 50 turns of copper wire of conductive diameter $0.4 \mathrm{~mm}$ onto a $5 \mathrm{~mm}$ diameter carbonyl powdered iron core (Micrometals, U. S. A). A larger diameter wire than used in (19) allows the coil to have a much lower resistance, increasing the current. We have reduced the windings from 70 (19) to 50 . The smaller number of turns decreases the inductance in the coil and allows a rapid change in current, which will increase the $E$-field strength (19). We used carbonyl powdered iron core (Micrometals, U.S.A) as a substitute to the soft-ferrite core (19) since it has a higher saturation magnetization (about $1.5 \mathrm{~T}$ ) than ferrite (about $0.4 \mathrm{~T}$ ). However, powdered iron cores have lower permeability than ferrite due to their air-gap distribution. The length of the untapered powdered iron core was $A$ $=19 \mathrm{~mm}$ and the diameter $B=5 \mathrm{~mm}$. In an attempt to increase focality of the fields, we tapered the core over the final $C=3 \mathrm{~mm}$ of its length to a diameter of $D=2 \mathrm{~mm}$, by careful sanding. The coil was also tapered in shape. Its total height was $E=12 \mathrm{~mm}$ and its diameter at the nontapered end was $F=9 \mathrm{~mm}$. It was tapered over its final $G=3 \mathrm{~mm}$ of length to a diameter of just $H=4 \mathrm{~mm}$. The coil is shown in Figure 2. The electrical parameters of the coil such as resistance and resistance of the coil against frequency was measured with an Agilent E4980A four-point impedance meter (Agilent Instruments, Santa Clara, California, USA).

We created a TMS pulse by discharging a $220 \mu \mathrm{F}$, capacitor at $50 \mathrm{~V}$ through the coil. The circuit was closed by gating an AUIRL3705N low on-resistance (10 $\mathrm{m} \Omega$ ) Metal-Oxide Semiconductor Field Effect Transistor (MOSFET) at $10 \mathrm{~V}$. The gate voltage was provided by boosting the output from an Arduino with an operational amplifier. The Arduino can be programmed to provide specific stimulation protocols. In this work we have used two protocols: 1200 pulses (80 seconds) of continuous theta burst stimulation at 3 pulses per burst and 5 bursts per second, and 1200 pulses (400 seconds) of intermittent theta burst stimulation at 3 pulses per burst and 5 bursts per second repeated for 2 seconds ON and 8 seconds OFF. 


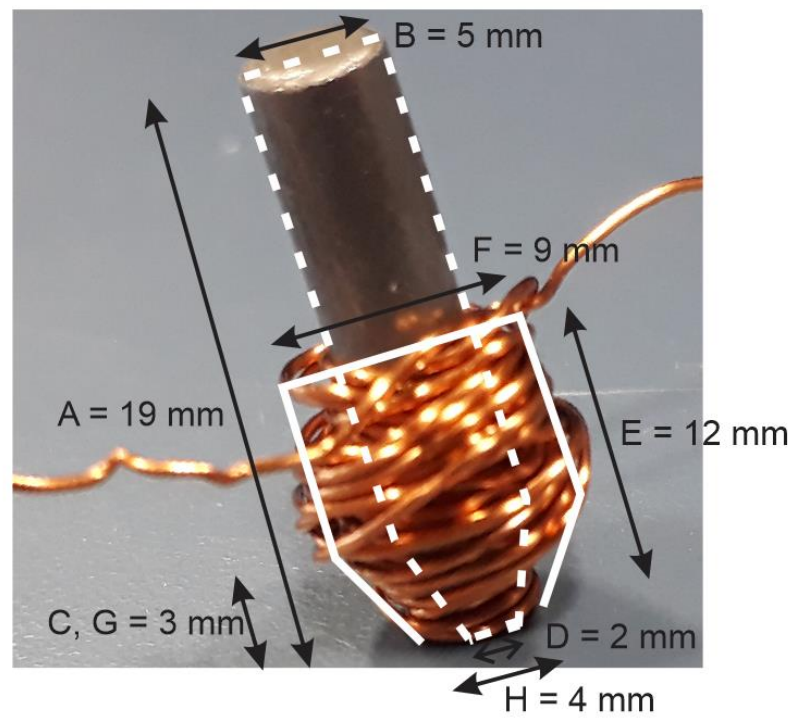

Figure 2. A photograph of the coil. 50 turns of conductive diameter of copper wire $(0.4 \mathrm{~mm})$. The dimensions of the core and coil are shown on the figure. The solid line shows the approximate shape of the coil and the dashed line the shape of the core.

\subsection{Coil modelling}

We have modelled the electromagnetic fields of the coil using COMSOL Multiphysics with 2$\mathrm{D}$ axial symmetry. The maximum current in the coil was estimated to be at most $140 \mathrm{~A}$ by assuming that the electrostatic energy in the 220 microfarad capacitor at $50 \mathrm{~V}$ is completely transferred to magnetic energy in the coil, using the measured value of the coil inductance (27.1 microhenry). A frequency of $1000 \mathrm{~Hz}$ was used.

\subsection{Measurement of field strength and distribution}

The $B$-field was measured on-axis as a function of distance below the coil, and at $2 \mathrm{~mm}$ below coil as a function of radial distance, using an A1302KUA-T Hall effect sensor (ALLEGRO MICROSYSTEMS). The corresponding $E$-field was measured as a function of radial distance, $2 \mathrm{~mm}$ below the coil, by measuring the voltage induced around a thin loop of wire. A thin loop of wire is oriented in such a way that the long sides were perpendicular to the $E$-field direction (39). The induced voltage around the loop divided by the length of the short side ( $3 \mathrm{~mm}$ ) gives the approximate $E$-field. We have chosen $2 \mathrm{~mm}$ distance below the coil because it is approximates the distance from the coil to the mouse cortex in mice experiments (26). 


\subsection{In vitro experiments}

The brain slice experiments used for this research were approved by the Animal Ethics Committee at the University of Waikato (Hamilton, New Zealand). The experiments were performed in a Faraday shielded room to control electrical noise interference.

We prepared 10 coronal brain slices from 5 mice $(2$ slices from each mouse) for iTBS experiments and 10 coronal brain slices from 3 mice ( 3 or 4 slices from each mouse) for cTBS experiments. Mice were of both sexes with the genetic background C57. Their age varied from 4 to 10 months old. They were housed in a temperature-controlled room with unlimited access to food and water. The mice were anesthetized with carbon dioxide and decapitated. The brain was dissected and placed in ice-cold HEPES-buffered 'normal' artificial cerebrospinal fluid (aCSF), oxygenated with $95 \%$ oxygen (Perfecto 2 oxygen concentrator, Invacare, New Zealand). HEPES (4-(2-hydroxyethyl)-1-piperazineethanesulfonic acid) is a zwitterionic sulfonic acid buffering agent. The farmost posterior and anterior coronal sections of the brain were removed with a razor blade. The remaining brain (approximately between Bregma 1 and $-5 \mathrm{~mm}$ ) was glued onto a metallic plate, placed into oxygenated ice-cold HEPES-buffered 'normal' aCSF, and coronally sectioned into slices 400 microns thick (Vibratome, Campden Instruments Ltd., United Kingdom). HEPES 'normal' artificial cerebrospinal fluid contained $130 \mathrm{mM}$ sodium chloride, $2.5 \mathrm{mM}$ potassium chloride, $1 \mathrm{mM}$ magnesium chloride, $2 \mathrm{mM}$ calcium chloride, $10 \mathrm{mM}$ HEPES and $20 \mathrm{mM}$ D-glucose in double distilled water. The aCSF was oxygenated with 95\% oxygen (Perfecto2 oxygen concentrator, Invacare, New Zealand). After the brain slices were sectioned, they were moved into oxygenated HEPES-buffered 'nomagnesium' aCSF for a minimum 1-hour recovery at room temperature. The 'no magnesium' aCSF contained $130 \mathrm{mM}$ sodium chloride, $5 \mathrm{mM}$ potassium chloride, $2 \mathrm{mM}$ calcium chloride, $10 \mathrm{mM}$ HEPES and $20 \mathrm{mM}$ D-glucose. The $\mathrm{pH}$ level of all solutions was adjusted to 7.4 with $10 \mathrm{M}$ sodium hydroxide. Apart from HEPES (ITW Reagents, Spain) and sodium chloride (EMSURE, Denmark), the aCSF ingredients were obtained from Sigma (USA).

Following the minimum recovery period, one slice at a time was moved to a submersion-style perfusion bath (Kerr Scientific Instruments, New Zealand). The perfusion bath was replenished continuously with oxygenated 'no-magnesium' aCSF by gravity-feed at a rate of $5 \mathrm{ml} / \mathrm{min}$. We clamped the coil above the perfusion bath where the slice was resting. We positioned a 75 micron diameter silver/silver chloride (GoodFellow Ltd., United Kingdom) electrode in layer IV of the mouse cortex as (Figure 3) to record spontaneous local field potential (LFP) activity. 
bioRxiv preprint doi: $h$ ttps://doi.org/10.1101/2020.01.09.900993; this version posted January 10, 2020. The copyright holder for this preprint (which was not certified by peer review) is the author/funder, who has granted bioRxiv a license to display the preprint in perpetuity. It is made available under aCC-BY-NC 4.0 International license.

The analog signal was recorded via a headstage placed in close proximity to the slice preparation. The signal was amplified 1000 times, low pass $(300 \mathrm{~Hz})$ and high pass $(1 \mathrm{~Hz})$ filtered (Model 3000 differential amplifier, A-M Systems, USA) and converted to a digital signal [Power-lab, ADInstruments, Australia]). The amplified and filtered signal was stored for later analysis.
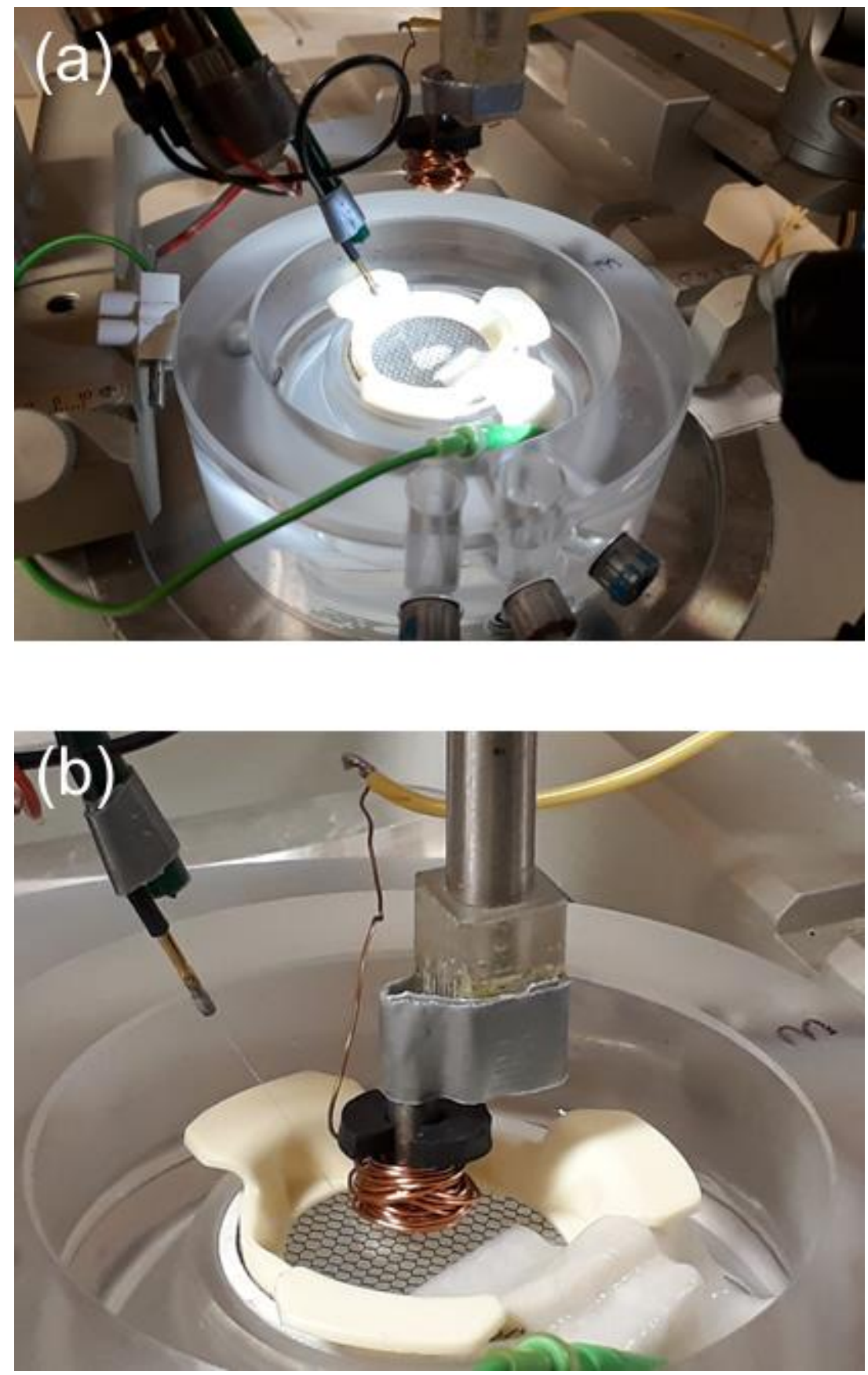

Figure 3. The set-up for the in vitro experiments. (a) The slice with recording electrode in place. (b) The coil in position for TMS application $2 \mathrm{~mm}$ above the slice. 
We analysed the spontaneous seizure-like events (SLEs) in terms of amplitude and inter-event frequency. The amplitude of an SLE is defined as the maximum (peak) value of the LFP minus the minimum (trough) value during the course of a single SLE. The inter-event frequency is defined as the number of events in a given time interval (in the case of this work, 10 minutes) divided by the time interval. Of the 20 slices, 10 were used for cTBS and 10 for iTBS experiments. Each slice received both stimulation and sham treatments, but half received stimulation first, and half received sham first. For stimulation, the coil was clamped $2 \mathrm{~mm}$ above the slice (touching the slice perfusion fluid). For sham treatment the coil was clamped $20 \mathrm{~mm}$ above the slice and thus received much lower EM field strengths. For the stimulationfirst slices, the timeline consisted of 15 minutes baseline recording of SLEs, then 1200 pulses of TBS (either cTBS or iTBS), then 30 minutes of SLE recording. This was followed by 1200 pulses of sham stimulation (cTBS or iTBS) and 30 more minutes of SLE recording. Figure 4 parts (a) and (c) show these sequences for cTBS and iTBS respectively. For the sham-first slices, the timeline was the same, except that the order of sham and stimulation was reversed. These sequences are shown in Figure 4 parts (b) and (d) for cTBS and iTBS respectively.

Post-stimulation and post-sham LFPs were analysed in three 10-minute segments, specifically 0-10 min, 10-20 min and 20-30 min after stimulation or sham. Average SLE amplitude and inter-event frequency were computed in each segment and the relative changes compared with the baseline were calculated. For the second stimulation in a protocol (i.e. the sham stimulation of Figure 4 (a) and (c), or the cTBS and iTBS of Figure 4 (b) and (d) respectively) the activity in the 10-minute segment immediately before the second stimulation was used as the baseline.

(a)

SLE recording cTBS SLE recording sham SLE recording

(b)
SLE recording sham SLE recording
cTBS SLE recording

(c)

\begin{tabular}{|l|l|l|l|l}
\hline SLE recording & iTBS & sLE recording & SLE recording \\
\hline
\end{tabular}

(d)

\begin{tabular}{|l|l|l|l|l}
\hline SLE recording & sham & SLE recording & iTBS & SLE recording \\
\hline
\end{tabular}

Figure 4. The timeline of the protocols. (a) For the cTBS experiments, activity from five slices was recorded for 15 minutes (baseline), then the slice was subjected to 1200 pulses of cTBS. 
The activity was then recorded for 30 minutes, before a sham stimulation and 30 minutes recording. (b) Also for cTBS, five more slices were stimulated as for (a), but with the order of cTBS and sham stimulation reversed. $(c)$ and $(d)$ For the iTBS experiments, the timeline was as for cTBS, except that the cTBS stimulation was replaced with iTBS. Five slices were stimulated with iTBS first, and another five with sham first.

\section{Results}

\subsection{Electrical properties of the coil}

Figure 5 (a) shows the resistance of the coil as a function of frequency. It is constant at about $212 \mathrm{~m} \Omega$ for frequencies less than around $10 \mathrm{kHz}$ and begins to rise for higher frequencies. We are particularly interested in frequencies of around $10 \mathrm{kHz}$ since the timescale of the TMS pulse is the order of $0.1 \mathrm{~ms}$ and therefore the increased resistance due to higher frequencies is unlikely to be a problem (19). The reactance of the coil shows a linear behaviour with frequency, shown in Figure 5 (b). The inductance of the coil is constant at about $27.1 \mu \mathrm{H}$ across the frequency range.

(a)

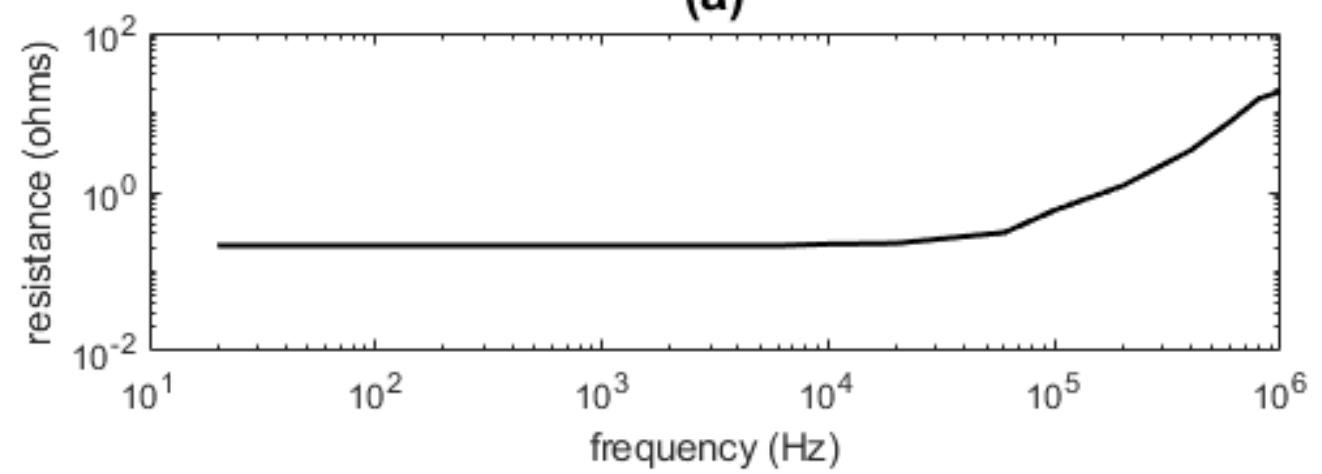

(b)

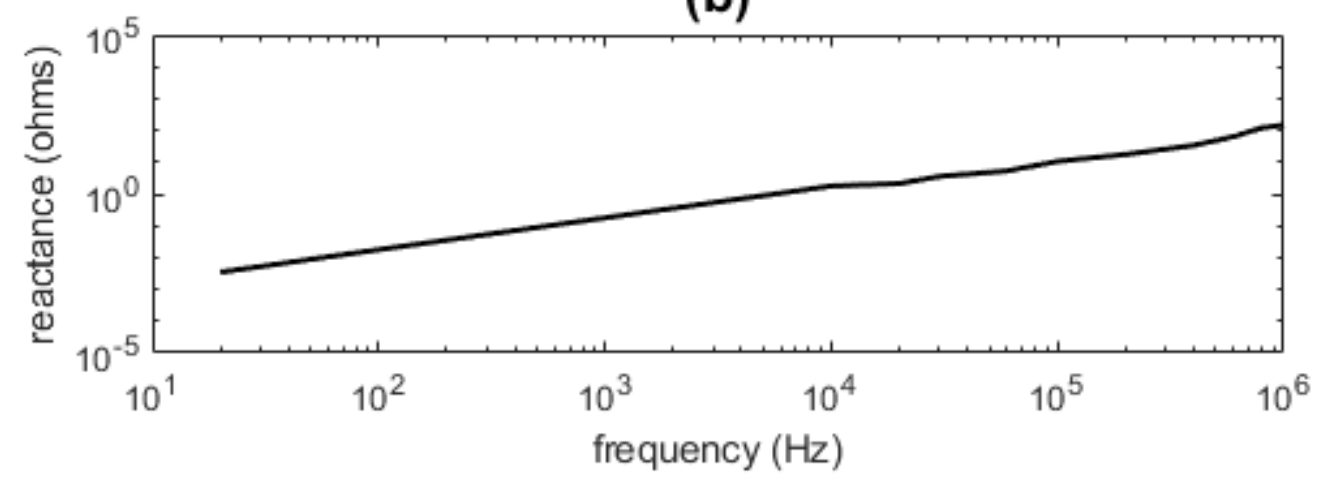

Figure 5. The electrical properties of 50 turn tapered powdered iron coil as measured with an Agilent E4980A four-point impedance meter. (a) The resistance of the 50 turn tapered 
powdered iron coil as a function of frequency. (b) The reactance of the 50 turn tapered powdered iron coil as a function of frequency.

\subsection{B-field and E-field}

The $B$-field strength at the base of the coil as a function of time for $50 \mathrm{~V}$ supply is shown in Figure 6 (a). The $B$-field peaks at $1.2 \mathrm{~T}$ about $0.1 \mathrm{~ms}$ after stimulation. The $B$-field as a function of supply voltage is shown in Figure 6 (b). It grows approximately linearly with supply voltage for voltages up to around $20 \mathrm{~V}$, before reducing in its response. However, at $50 \mathrm{~V}$ supply, the field still shows significant increase in strength with increasing voltage, suggesting that the core has still not fully saturated. The spatial distribution of the $B$-field is shown in Figure 7 . The decay of the $B$-field strength with axial displacement is shown in part (a). The full-width at half maximum is around $3 \mathrm{~mm}$, showing significant focality. The decay with on-axis distance is shown in part (b). The $B$-field measured at $2 \mathrm{~mm}$ below the coil, on axis, was $760 \mathrm{mT}$.

(a)

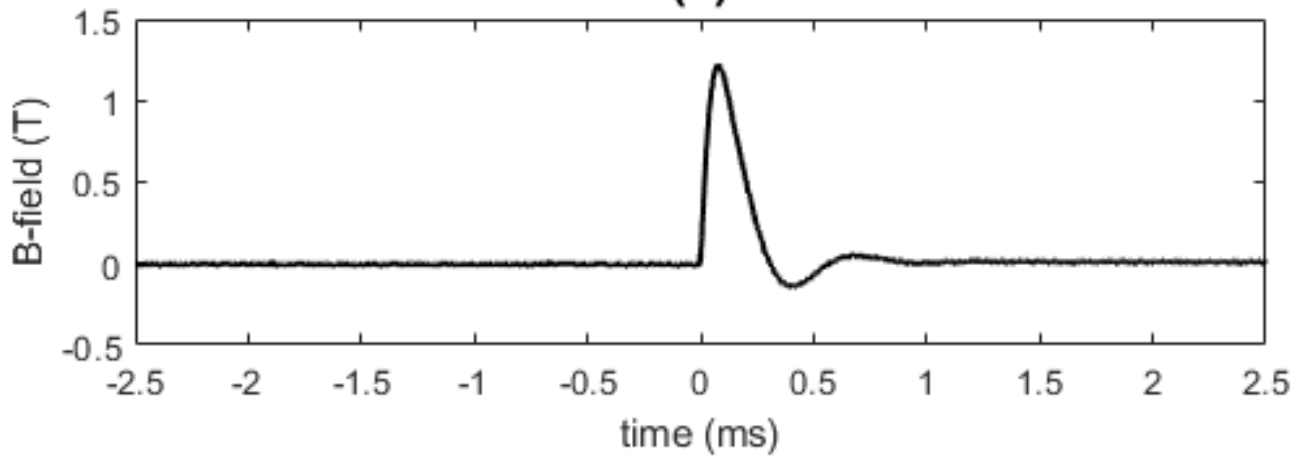

(b)

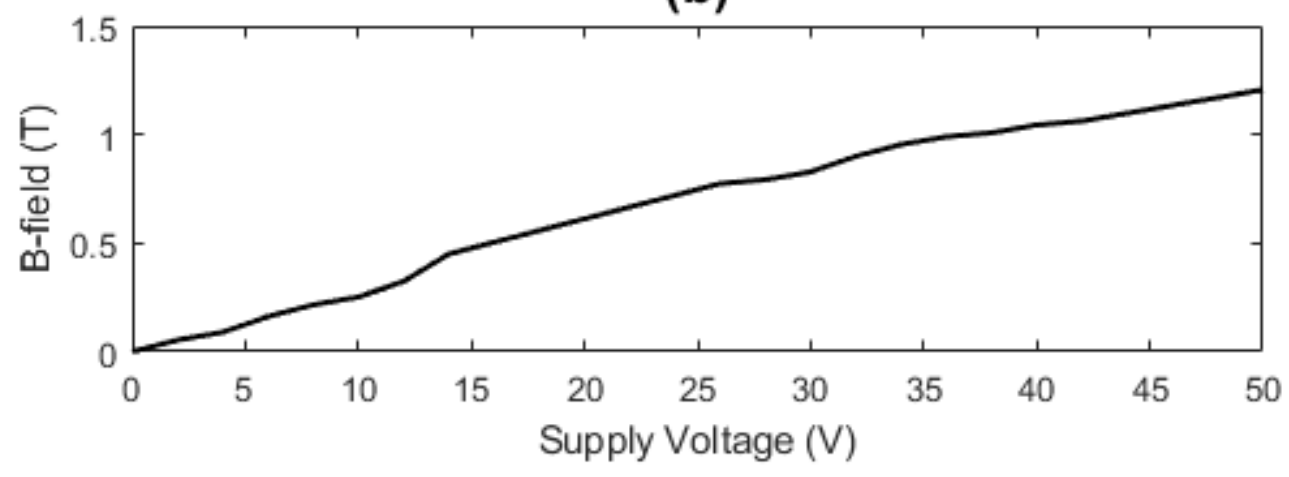

Figure 6. The B-field strengths against time and supply voltages across $50 \mathrm{~V}$. (a) The B-field against time for a typical pulse, $0 \mathrm{~mm}$ below the coil. (b) The on-axis B-field $0 \mathrm{~mm}$ below the coil against supply voltage. 
(a)

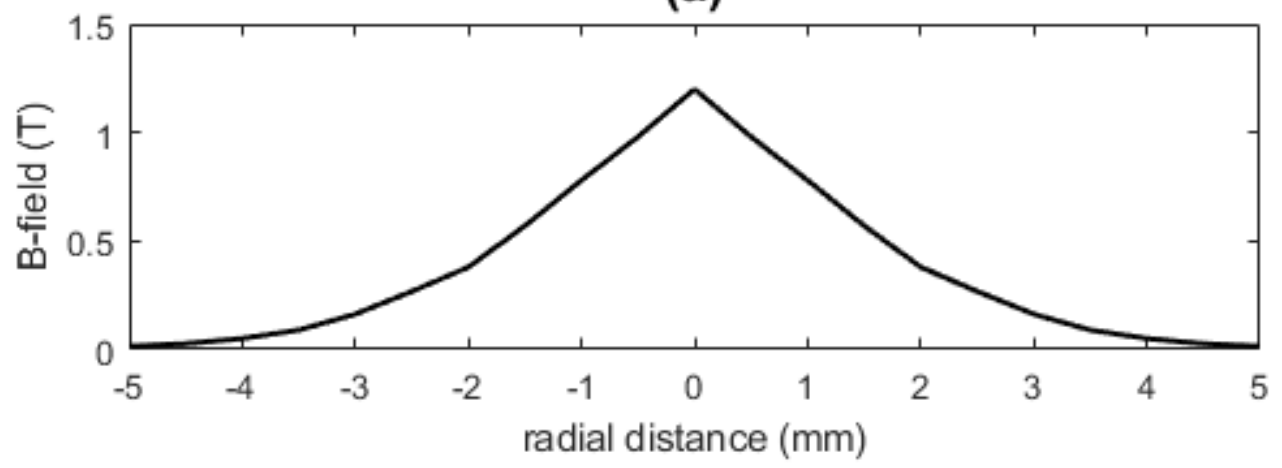

(b)

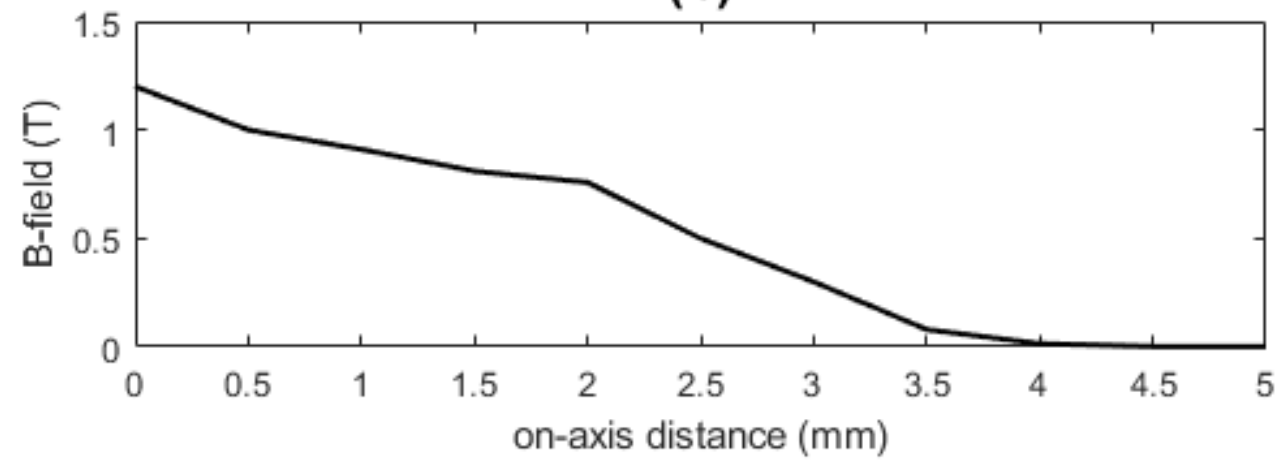

Figure 7. The spatial distribution of the B-field. (a) The B-field as a function of radial distance from the axis of the coil measured at $0 \mathrm{~mm}$ along the axis of the coil at $50 \mathrm{~V}$. Negative axis values corresponds to a measurement in the opposite direction from positive axis. (b) The Bfield as a function of on-axis distance below the coil at $50 \mathrm{~V}$.

Figure 8 shows the induced electric field, measured at a vertical distance of $2 \mathrm{~mm}$ below the coil. The $E$-field strength as a function of time is shown in Figure 8 (a). It shows a short pulse (around $0.1 \mathrm{~ms}$ duration) of $E$-field with a maximum strength of $32 \mathrm{~V} / \mathrm{m}$. The change of $E$ field with radial distance is shown in Figure 8 (b). The plot shows a maximum $E$-field at 0.5 $\mathrm{mm}$, however, we note significant uncertainty in the measurement of radial distance since the thin loop used to measure $E$-field was $3 \mathrm{~mm}$ in width. 
(a)

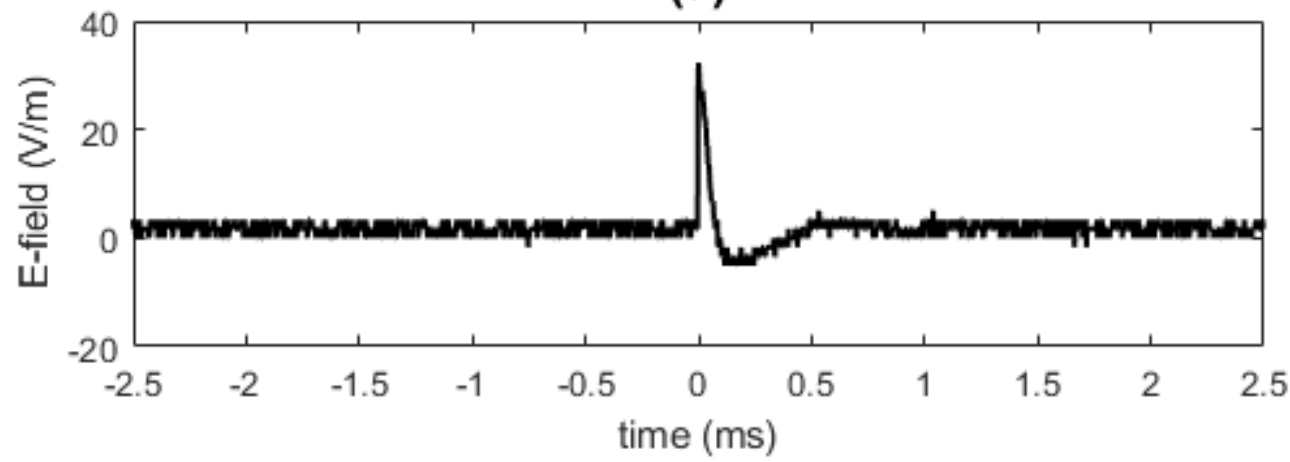

(b)

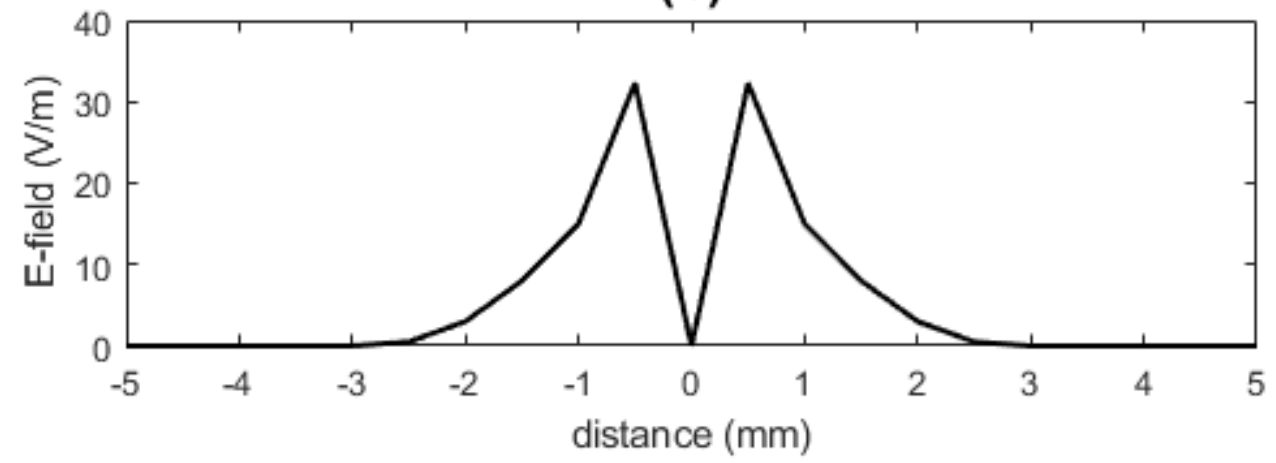

Figure 8. The E-field strengths as a function of time and space. (a) The E-field against time for a typical pulse at $50 \mathrm{~V}, 2 \mathrm{~mm}$ below the coil and at $0.5 \mathrm{~mm}$ radial displacement, measured with a wire loop and oscilloscope. (b) The E-field as a function of radial distance from the axis of the coil, measured at $2 \mathrm{~mm}$ below the coil at $50 \mathrm{~V}$. Negative distances corresponds to a measurement in the opposite direction to positive distances. Measurements of distance should be attributed significant uncertainty up to $1.5 \mathrm{~mm}$

Figures 9 and 10 show the results of modelling with COMSOL Multiphysics for the $B$ - and $E$-fields respectively. The left black outline shows the powdered iron core geometry and the right black outline shows the coil geometry as described in Figure 2. The modeled $B$-field 2 $\mathrm{mm}$ below the coil is $650 \mathrm{mT}-700 \mathrm{mT}$ and the corresponding maximum E-field is $30-32$ $\mathrm{V} / \mathrm{m}$, consistent with measurement. However, the maximum $E$-field occurs at a distance of 2 $\mathrm{mm}$ from the axis, much larger than the measurements of Figure 8. In practice, the fields are more focused than the modelling predicts. We have not investigated this discrepancy further but note that it might be a consequence of the unphysically sharp corners used in finiteelement COMSOL approach, or uncertainties in the measurement process. 


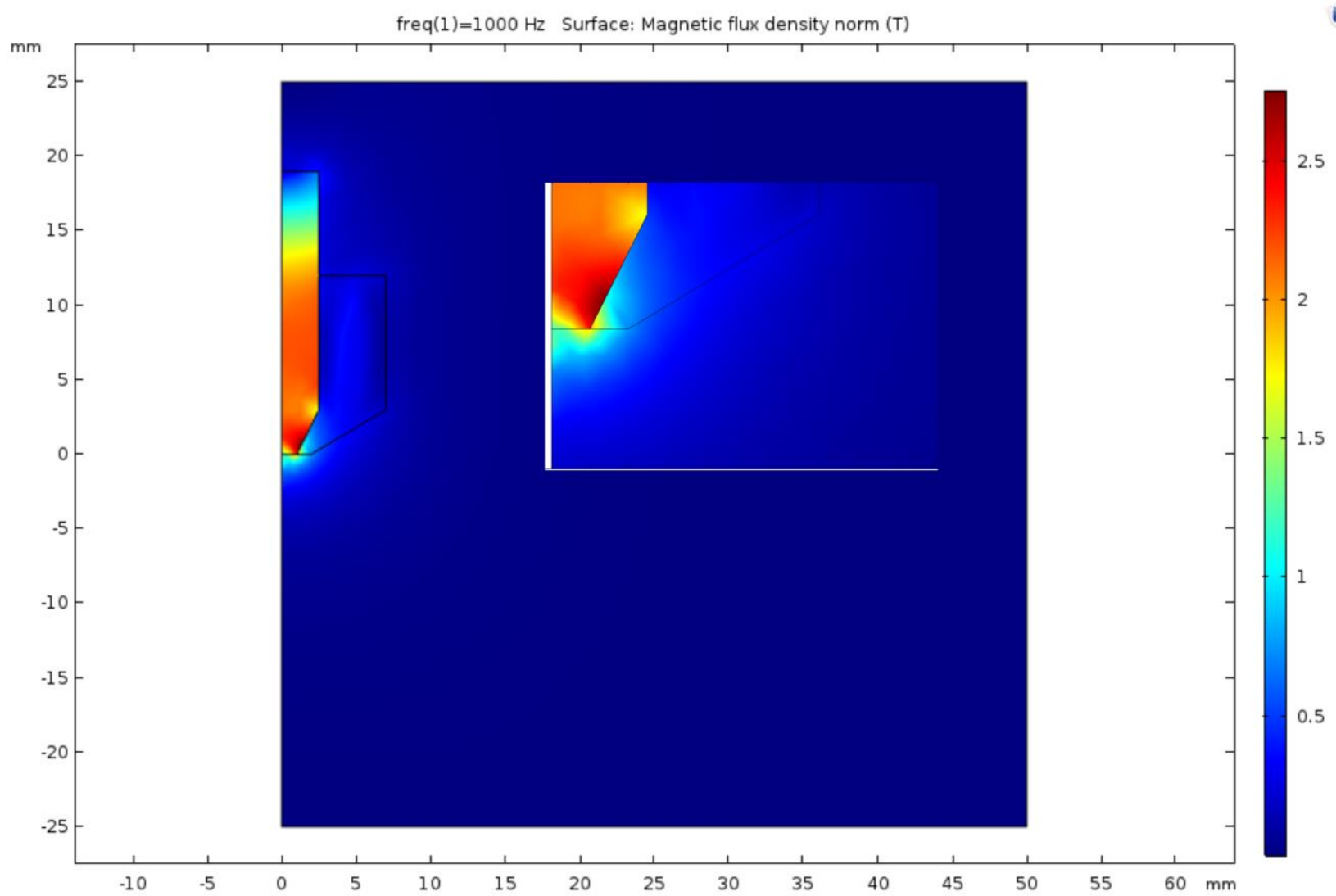

Figure 9. The B-field modelled with COMSOL Multiphysics using 2-D axial symmetry. The right side of the figure is representing the magnified part of the original figure that shows the magnetic field strength, $2 \mathrm{~mm}$ below the coil. 


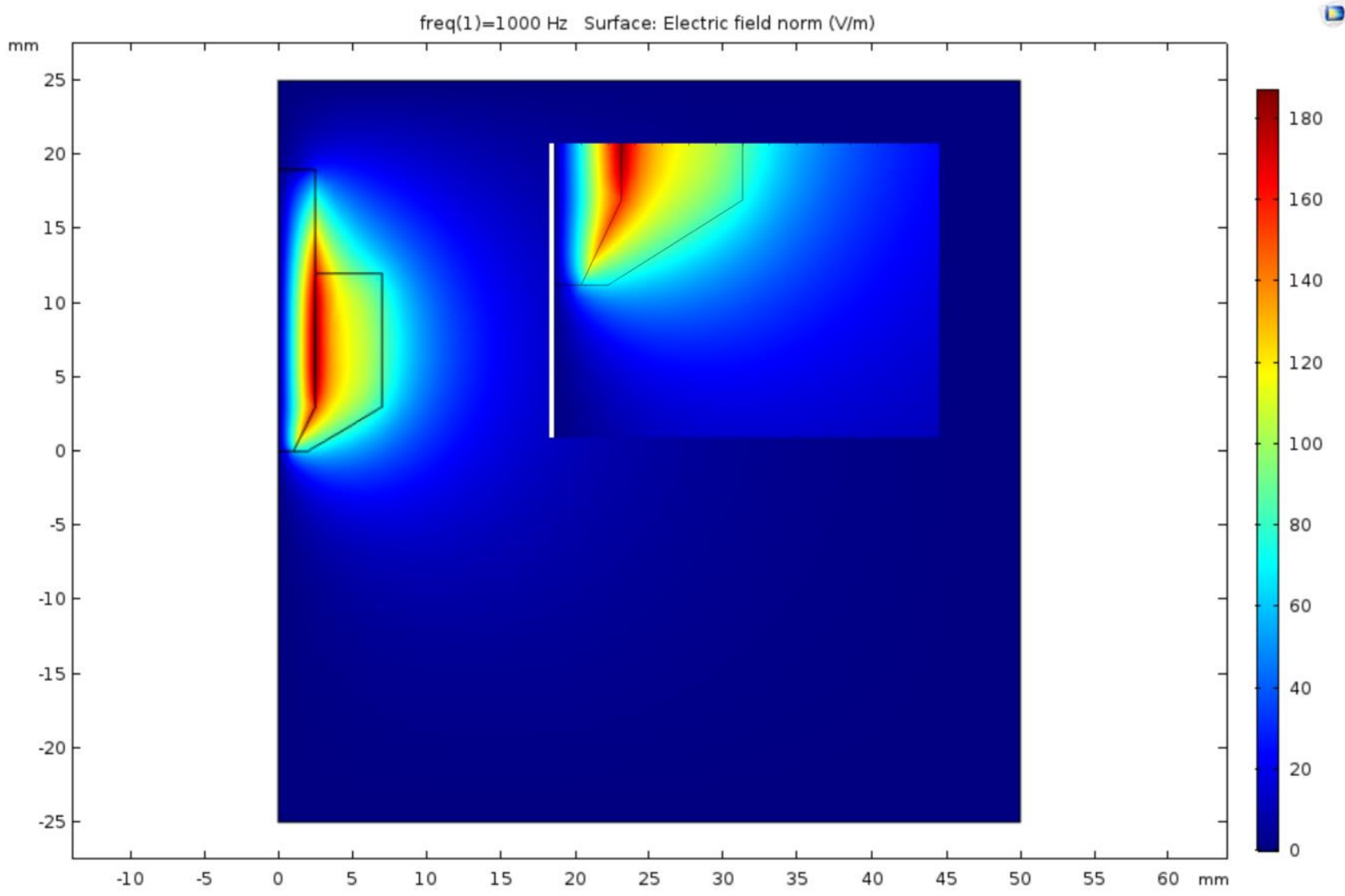

Figure 10. The E-field modelled with COMSOL Multiphysics using 2-D axial symmetry. . The right side of the figure is representing the magnified part of the original figure that shows the magnetic field strength, $2 \mathrm{~mm}$ below the coil.

\subsection{Temperature rise}

We have also measured the heating of the coil. For iTBS, the temperature of the coil rose by 10 degrees Celsius after 1200 pulses at 50 V power supply at room temperature of 22 degrees Celsius. For cTBS, the temperature of the coil rose by 20 degrees Celsius after 1200 at $50 \mathrm{~V}$ power supply at room temperature of 22 degrees Celsius. We have also recorded the temperature of the slice perfusion fluid during the experiments. It rose by just 0.2 Celsius after stimulation with 1200 pulses of cTBS (the same rise was also recorded after 1200 pulses of iTBS) with a background room temperature of 24.0 degrees Celsius. To test whether this increase in temperature affected SLE activity, we have independently measured SLE activity in a slice before and after raising the fluid temperature by 0.3 degrees Celsius through gentle heating. There was no change in SLE activity which suggests that any changes in SLE activity (results not shown) due to temperature change in this experiment are likely to be insignificant. 


\subsection{SLE activity}

We have measured the relative change in amplitude and frequency for each slice from its baseline. The relative change in amplitude from baseline after cTBS and sham stimulation is shown in Figure 11 for periods 0 - $10 \mathrm{~min}, 10$ - $20 \mathrm{~min}$ and 20 - $30 \mathrm{~min}$ after stimulation. A similar plot for the relative changes in frequency is shown in Figure 12. Figures 13 and 14 show the results of iTBS stimulation on amplitude and frequency respectively. For each experiment, we applied a 2-way repeated measures ANOVA (RMANOVA) to test for changes due to treatment group (TBS or sham) and time. Where changes were statistically significant, we applied post-hoc t-tests to the distributions for the TBS and sham groups. The cut-off pvalue for application of post-hoc t-test to the distributions are calculated as 0.0017 with the Bonferroni correction for 3 comparisons. For the changes in amplitude following cTBS, we obtained no statistical significance for either treatment group $(p=0.88)$ or time $(p=0.16)$. For changes in frequency following cTBS, we obtained a significant effect in both treatment group $(p=0.0053)$ and time $(p=0.024)$. For the changes in amplitude following iTBS, we see no effects either in treatment group $(p=0.060)$ or time group $(p=0.47)$; however, for changes in frequency we found a significant effect for the treatment group $(p=0.00094)$ but not for the time group $(p=0.098)$. Having established that the treatment group has an effect (the case for both cTBS and iTBS SLE frequency, but not SLE amplitude), we applied a post-hoc t-test to see where the effects were maximised. For frequency following cTBS, we see a significant decrease in SLEs inter-event frequency at $0-10 \mathrm{~min}(p=0.00034)$ and $10-20 \mathrm{~min}(p=0.0014)$ after stimulation, however, we see no change in 20-30 min after stimulation $(p=0.86)$. For frequency following iTBS, we see a significant increase in SLEs inter-event frequency at 0-10 $\min (p=0.00060)$ and 10-20 $\min (p=0.0015)$ after stimulation, however, no change at 20-30 min after stimulation $(p=0.021)$. 

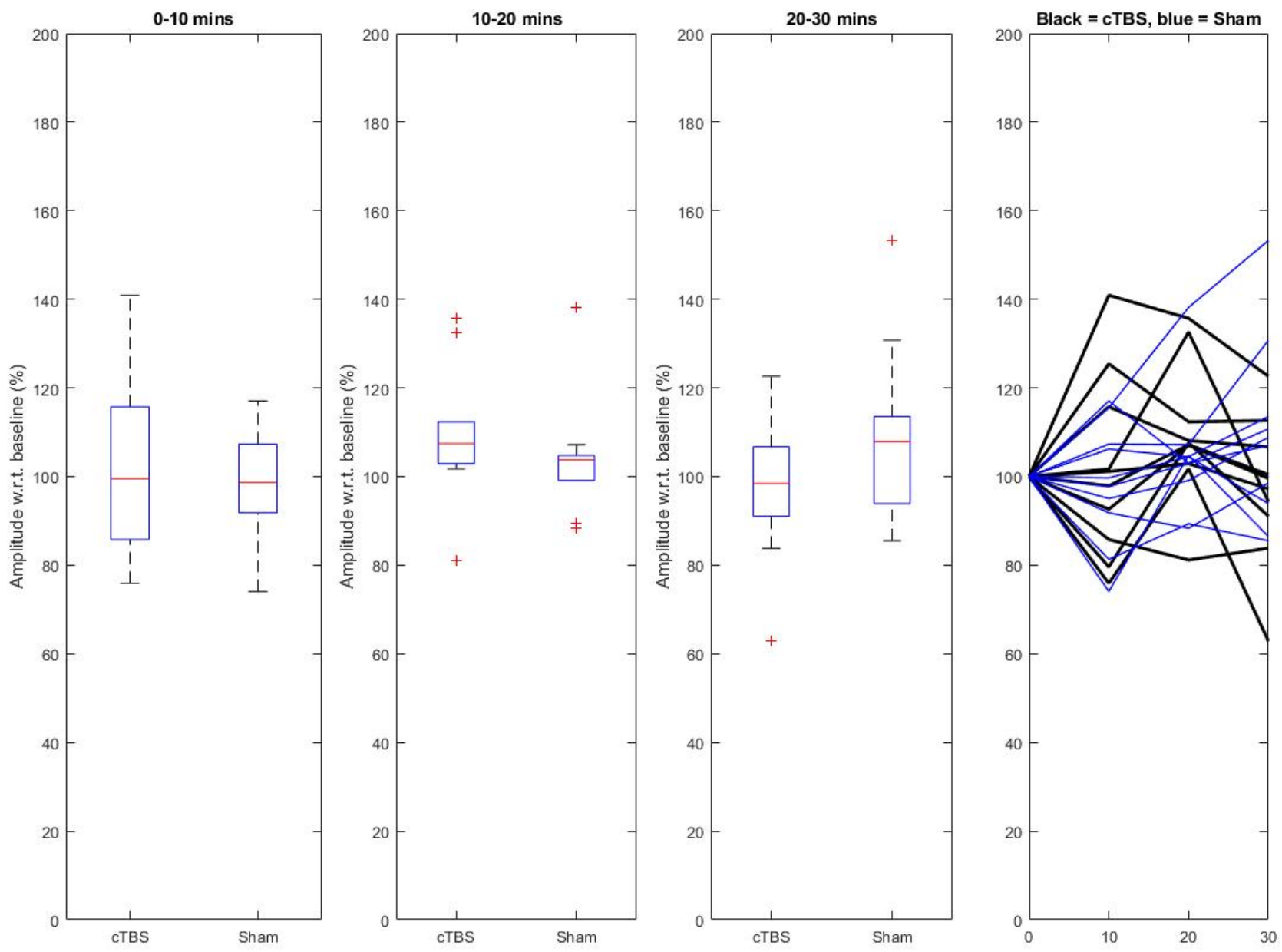

Figure 11. The relative change in SLE amplitude with respect to baseline for cTBS and sham stimulation for 0-10 $\mathrm{min}, 10-20 \mathrm{~min}$ and 20-30 min after stimulation. The fourth plot shows the response of the various individual slices; black denotes cTBS stimulation and blue sham. 

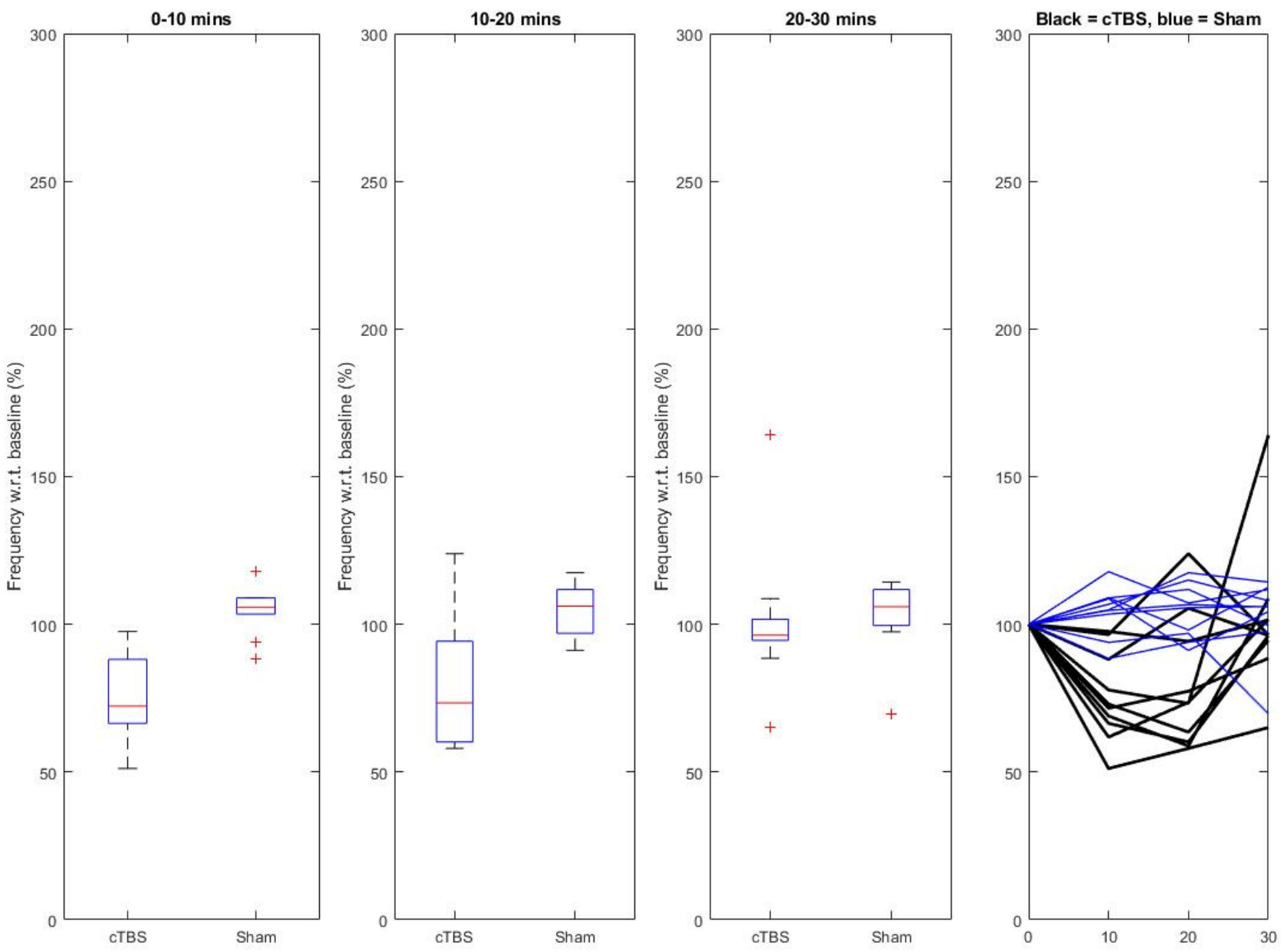

Figure 12. The relative change in SLE frequency after cTBS and sham stimulation for 0-10 min, 10-20 min and 20-30 min after stimulation. The fourth plot shows the response of the various individual slices; black denotes cTBS stimulation and blue sham. 

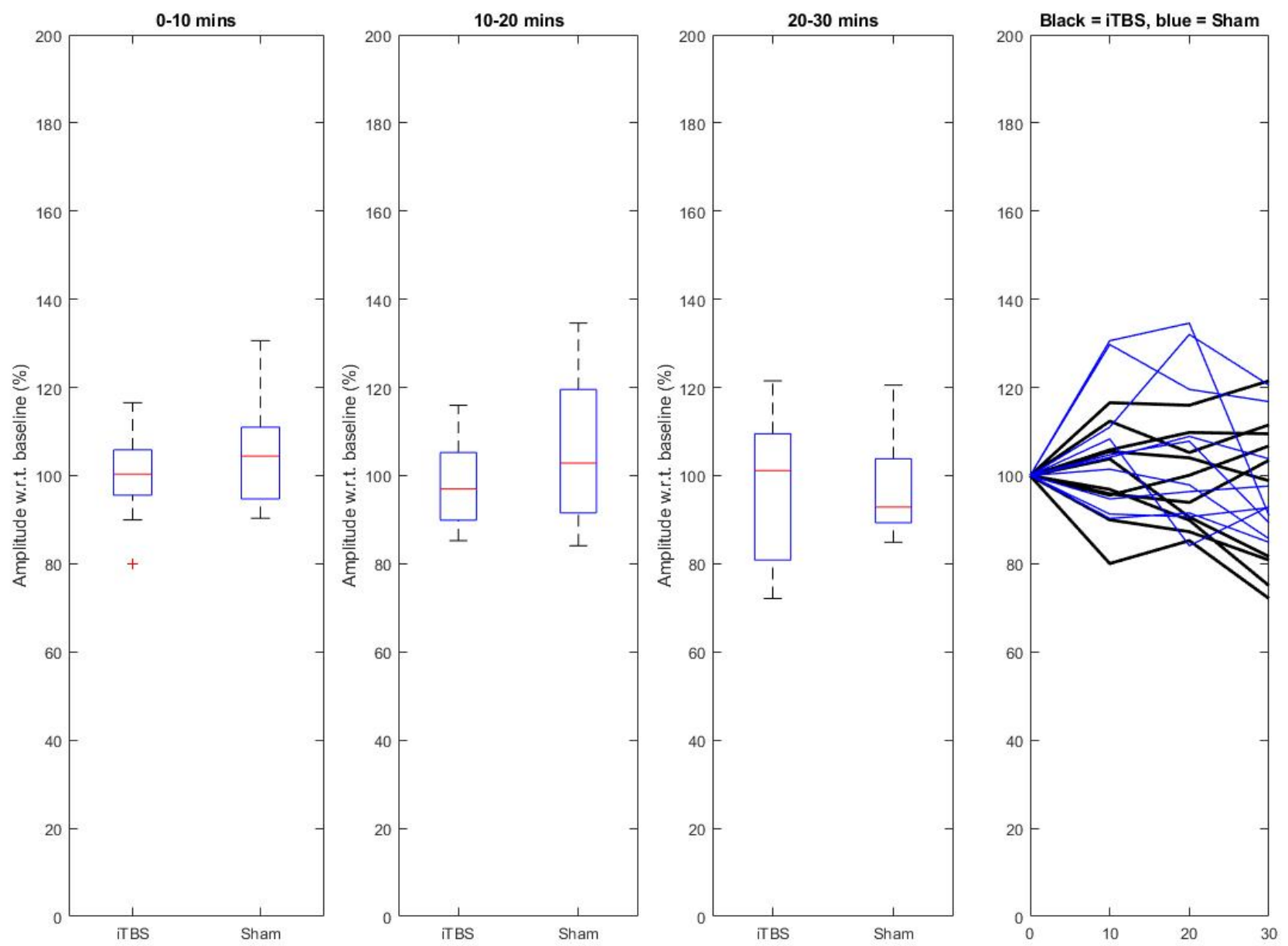

Figure 13. The relative change in SLE amplitude after iTBS and sham stimulation for 0-10 min, 10-20 min and 20-30 min after stimulation. The fourth plot shows the response of the various individual slices; black denotes iTBS stimulation and blue sham. 

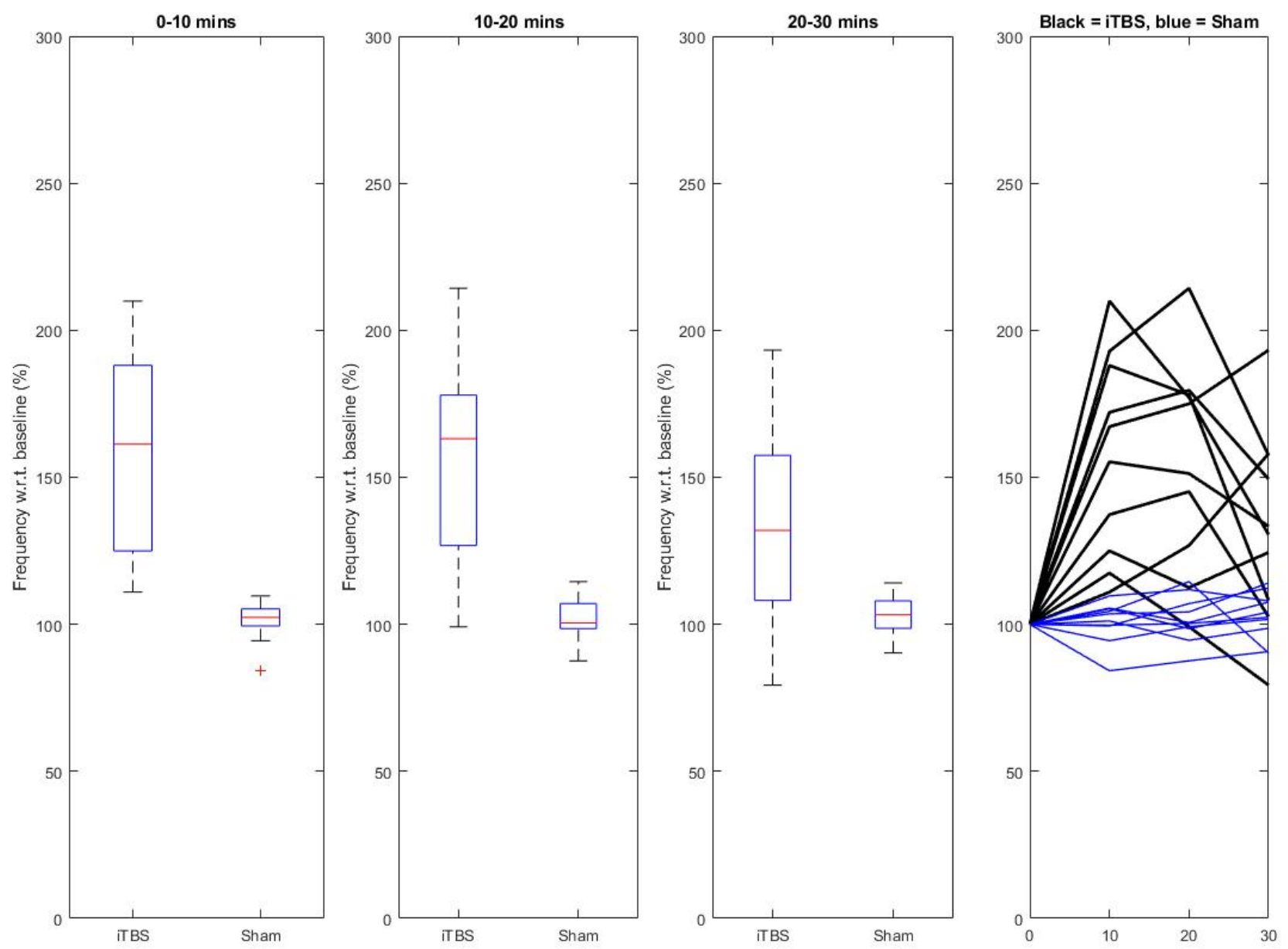

Figure 14. The relative change in SLE frequency after $i T B S$ and sham stimulation for $0-10$ min, 10-20 min and 20-30 min after stimulation. The fourth plot shows the response of the various individual slices; black denotes iTBS stimulation and blue sham.

\section{Discussion}

We have constructed a tapered mouse-specific TMS coil that exhibits stronger and more focused electromagnetic field strengths, $2 \mathrm{~mm}$ above the surface of the brain than the previously constructed small-scale coils $(19,28,56)$. Significant changes have been the reduction in the number of turns, the selection of a high saturation magnetization core material, and a tapering of one end of the core to focus the $B$-field and increase and focus the $E$-field. However, the field strengths, notably the $E$-field, are still much lower than the human TMS coils. Since we have measured and modeled fields in free-space, it is likely that the geometry of the brain surface could lead to localised increases in this value (28). Additionally, the region of strong $E$-field is still annular in shape, although the tapering of the core has reduced the radius of the annulus. The coil design, having a significant thickness of turns around a central core, would need some modification before two could be implemented in a figure-of-eight style 
to further focus the field at a small point. There are several remaining challenges. Heating is a major problem in small-scale coils. This is because the reduction of a coil in radius and coil length will produce ten-fold increase in heating (19). At $50 \mathrm{~V}$ power supply, the temperature rise of the coil after 1200 pulses of cTBS was 20 degrees Celsius, with larger voltages expected to give significantly increased heating. The primary source of heating is resistive heating in the coil; controlling this would likely mean using some form of external cooling such as a heat sink. A permeable core ensures high enough inductance to give a sufficient ring-down time (larger than about $0.5 \mathrm{~ms}$ ) in the inductor-capacitor circuit while keeping capacitance below a milliFarad, thus reducing the pulse energy and heating (19). However, this advantage is reduced when the core approaches saturation, and the B-field strengths obtained (1.2 T) are close to the expected saturation flux density (about $1.5 \mathrm{~T}$ ). It is possible that further improvement could be made by more sophisticated shaping of the core and coil.

We have demonstrated that the electromagnetic fields, although weaker than in the human case, are sufficient to cause biophysical changes in a brain slice over a time scale of 20 minutes when applied as cTBS or iTBS. The cTBS resulted in a decrease in frequency of SLE activity, whereas iTBS had an opposite effect. However, responses are highly variable between slices (Figures 12 and 14, final panels). These results are broadly consistent with the canonical decrease and increase in excitability following human cTBS and iTBS respectively $(57,58)$, although significant effects in our measurements were limited to 20 minutes after stimulation. We emphasize that our method measures the local field potential due to spontaneous activity, and does not in itself shed light on the biophysical mechanisms of TMS. However, more discriminating experimental methods to assess plasticity and excitability of the cortex or other brain areas $(59,60)$ could be implemented.

\section{Conclusion}

We have demonstrated a small TMS coil suitable for applying TMS to a mouse. While the $B$ field strength is close to that achieved by some human coils, the E-field strength is still substantially lower. However, we have demonstrated that such fields are still sufficient to change the biophysical behaviour of mouse cortex in-vitro through theta-burst stimulation.

\section{Acknowledgements}

The research was conceived by MTW. FAK and MTW designed the coil and FAK measured its fields. ASR advised on the methods. LJV prepared the brain slices and FAK carried out the 
bioRxiv preprint doi: https://doi.org/10.1101/2020.01.09.900993; this version posted January 10,2020 . The copyright holder for this preprint (which was not certified by peer review) is the author/funder, who has granted bioRxiv a license to display the preprint in perpetuity. It is made available under aCC-BY-NC 4.0 International license.

in vitro recording. MTW and FAK analyzed the data with advice from ASR. All authors contributed to the writing of the manuscript.

\section{References}

1. Barker AT, Shields K. Transcranial magnetic stimulation: basic principles and clinical applications in migraine. Headache: The Journal of Head and Face Pain. 2017;57(3):517-24.

2. Terranova C, Rizzo V, Cacciola A, Chillemi G, Calamuneri A, Milardi D, et al. Is there a future for non-invasive brain stimulation as a therapeutic tool? Frontiers in neurology. 2019;9.

3. Loo CK, Mitchell PB. A review of the efficacy of transcranial magnetic stimulation (TMS) treatment for depression, and current and future strategies to optimize efficacy. J Affect Disord. 2005;88(3):255-67.

4. O'Reardon JP, Solvason HB, Janicak PG, Sampson S, Isenberg KE, Nahas Z, et al. Efficacy and safety of transcranial magnetic stimulation in the acute treatment of major depression: a multisite randomized controlled trial. Biol Psychiatry. 2007;62(11):1208-16.

5. Ridding MC, Ziemann U. Determinants of the induction of cortical plasticity by non-invasive brain stimulation in healthy subjects. J Physiol. 2010;588(Pt 13):2291-304.

6. Cincotta M, Borgheresi A, Gambetti C, Balestrieri F, Rossi L, Zaccara G, et al. Suprathreshold $0.3 \mathrm{~Hz}$ repetitive TMS prolongs the cortical silent period: potential implications for therapeutic trials in epilepsy. Clinical Neurophysiology. 2003;114(10):1827-33.

7. Yang $\mathrm{C}$, Guo Z, Peng H, Xing G, Chen H, McClure MA, et al. Repetitive transcranial magnetic stimulation therapy for motor recovery in Parkinson's disease: A Meta-analysis. Brain Behav. 2018;8(11):e01132.

8. Wu AD, Fregni F, Simon DK, Deblieck C, Pascual-Leone A. Noninvasive brain stimulation for Parkinson's disease and dystonia. Neurotherapeutics. 2008;5(2):345-61.

9. Kimberley TJ, Schmidt RL, Chen M, Dykstra DD, Buetefisch CM. Mixed effectiveness of rTMS and retraining in the treatment of focal hand dystonia. Front Hum Neurosci. 2015;9:385.

10. Stinear CM, Byblow WD. Impaired modulation of intracortical inhibition in focal hand dystonia. Cereb Cortex. 2004;14(5):555-61.

11. Guerra A, Assenza F, Bressi F, Scrascia F, Del Duca M, Ursini F, et al. Transcranial magnetic stimulation studies in Alzheimer's disease. Int J Alzheimers Dis. 2011;2011:263817.

12. Marron EM, Viejo-Sobera R, Quintana M, Redolar-Ripoll D, Rodriguez D, Garolera M. Transcranial magnetic stimulation intervention in Alzheimer's disease: a research proposal for a randomized controlled trial. BMC Res Notes. 2018;11(1):648.

13. Inghilleri M, Conte A, Frasca V, Scaldaferri N, Gilio F, Santini M, et al. Altered response to rTMS in patients with Alzheimer's disease. Clin Neurophysiol. 2006;117(1):103-9.

14. Dong $X$, Yan L, Huang L, Guan X, Dong C, Tao H, et al. Repetitive transcranial magnetic stimulation for the treatment of Alzheimer's disease: A systematic review and meta-analysis of randomized controlled trials. PLoS One. 2018;13(10):e0205704.

15. Hallett M. Transcranial magnetic stimulation: a primer. Neuron. 2007;55(2):187-99.

16. Ridding MC, Rothwell JC. Is there a future for therapeutic use of transcranial magnetic stimulation? Nature Reviews Neuroscience. 2007;8(7):559.

17. Rastogi $P$, Hadimani $R$, Jiles $D$. Investigation of coil designs for transcranial magnetic stimulation on mice. IEEE Transactions on Magnetics. 2016;52(7):1-4.

18. Rastogi P, Lee EG, Hadimani RL, Jiles DC. Transcranial Magnetic Stimulation-coil design with improved focality. AIP Advances. 2017;7(5).

19. Wilson MT, Tang AD, lyer K, McKee H, Waas J, Rodger J. The challenges of producing effective small coils for transcranial magnetic stimulation of mice. Biomedical Physics \& Engineering Express. 2018;4(3). 
bioRxiv preprint doi: https://doi.org/10.1101/2020.01.09.900993; this version posted January $10,2020$. The copyright holder for this preprint (which was not certified by peer review) is the author/funder, who has granted bioRxiv a license to display the preprint in perpetuity. It is made available under aCC-BY-NC 4.0 International license.

20. Tang AD, Makowiecki K, Bartlett C, Rodger J. Low intensity repetitive transcranial magnetic stimulation does not induce cell survival or regeneration in a mouse optic nerve crush model. PloS one. 2015;10(5):e0126949.

21. Wilson MT, Goodwin DP, Brownjohn PW, Shemmell J, Reynolds JN. Numerical modelling of plasticity induced by transcranial magnetic stimulation. J Comput Neurosci. 2014;36(3):499-514.

22. Wilson MT, Fulcher BD, Fung PK, Robinson PA, Fornito A, Rogasch NC. Biophysical modeling of neural plasticity induced by transcranial magnetic stimulation. Clin Neurophysiol. 2018;129(6):1230-41.

23. Khedr EM, Gabra RH, Noaman M, Abo Elfetoh N, Farghaly HSM. Cortical excitability in tramadol dependent patients: A transcranial magnetic stimulation study. Drug Alcohol Depend. 2016;169:110-6.

24. Sykes M, Matheson NA, Brownjohn PW, Tang AD, Rodger J, Shemmell JB, et al. Differences in Motor Evoked Potentials Induced in Rats by Transcranial Magnetic Stimulation under Two Separate Anesthetics: Implications for Plasticity Studies. Front Neural Circuits. 2016;10:80.

25. Rodger J, Mo C, Wilks T, Dunlop SA, Sherrard RM. Transcranial pulsed magnetic field stimulation facilitates reorganization of abnormal neural circuits and corrects behavioral deficits without disrupting normal connectivity. The FASEB Journal. 2012;26(4):1593-606.

26. Rodger J, Sherrard RM. Optimising repetitive transcranial magnetic stimulation for neural circuit repair following traumatic brain injury. Neural regeneration research. 2015;10(3):357. 27. Matheson NA, Shemmell JB, De Ridder D, Reynolds JN. Understanding the effects of repetitive transcranial magnetic stimulation on neuronal circuits. Frontiers in neural circuits. 2016;10:67.

28. Tang AD, Lowe AS, Garrett AR, Woodward R, Bennett W, Canty AJ, et al. Construction and Evaluation of Rodent-Specific rTMS Coils. Front Neural Circuits. 2016;10:47.

29. Thickbroom GW. Transcranial magnetic stimulation and synaptic plasticity: experimental framework and human models. Experimental brain research. 2007;180(4):583-93.

30. Makowiecki K, Harvey AR, Sherrard RM, Rodger J. Low-intensity repetitive transcranial magnetic stimulation improves abnormal visual cortical circuit topography and upregulates BDNF in mice. Journal of Neuroscience. 2014;34(32):10780-92.

31. Vlachos A, Müller-Dahlhaus F, Rosskopp J, Lenz M, Ziemann U, Deller T. Repetitive magnetic stimulation induces functional and structural plasticity of excitatory postsynapses in mouse organotypic hippocampal slice cultures. Journal of Neuroscience. 2012;32(48):17514-23.

32. Lenz M, Galanis C, Müller-Dahlhaus F, Opitz A, Wierenga CJ, Szabó G, et al. Repetitive magnetic stimulation induces plasticity of inhibitory synapses. Nature communications. 2016;7:10020.

33. Hoogendam JM, Ramakers GM, Di Lazzaro V. Physiology of repetitive transcranial magnetic stimulation of the human brain. Brain stimulation. 2010;3(2):95-118.

34. Perlman RL. Mouse models of human diseaseAn evolutionary perspective. Evolution, medicine, and public health. 2016;2016(1):170-6.

35. Barnes WL, Lee WH, Peterchev AV, editors. Approximating transcranial magnetic stimulation with electric stimulation in mouse: a simulation study. 2014 36th Annual International Conference of the IEEE Engineering in Medicine and Biology Society; 2014: IEEE.

36. Lee $\mathrm{S}$, Jang K-I, Yoon S, Chae J-H. The efficacy of miniaturized repetitive transcranial magnetic stimulation in patients with depression. Clinical Psychopharmacology and Neuroscience. 2019;17(3):409.

37. Pawar A, Saldanha D, Chaudhury S, Ryali V, Srivastava K. Transcranial Magnetic Stimulation: A New Therapeutic Tool in Psychiatry. Medical journal, Armed Forces India. 2008;64(2):158.

38. George MS, Taylor JJ, Short EB. The expanding evidence base for rTMS treatment of depression. Current opinion in psychiatry. 2013;26(1):13.

39. Nieminen JO, Koponen LM, Ilmoniemi RJ. Experimental characterization of the electric field distribution induced by TMS devices. Brain stimulation. 2015;8(3):582-9. 
bioRxiv preprint doi: https://doi.org/10.1101/2020.01.09.900993; this version posted January $10,2020$. The copyright holder for this preprint (which was not certified by peer review) is the author/funder, who has granted bioRxiv a license to display the preprint in perpetuity. It is made available under aCC-BY-NC 4.0 International license.

40. Herculano-Houzel $S$. The human brain in numbers: a linearly scaled-up primate brain. Frontiers in human neuroscience. 2009;3:31.

41. Shih AY, Driscoll JD, Drew PJ, Nishimura N, Schaffer CB, Kleinfeld D. Two-photon microscopy as a tool to study blood flow and neurovascular coupling in the rodent brain. Journal of Cerebral Blood Flow \& Metabolism. 2012;32(7):1277-309.

42. Lanfer B, Scherg M, Dannhauer M, Knösche TR, Burger M, Wolters $\mathrm{CH}$. Influences of skull segmentation inaccuracies on EEG source analysis. Neurolmage. 2012;62(1):418-31.

43. Dayan E, Censor N, Buch ER, Sandrini M, Cohen LG. Noninvasive brain stimulation: from physiology to network dynamics and back. Nature neuroscience. 2013;16(7):838.

44. Pridmore S, Ang G. A water-cooled transcranial magnetic stimulation coil. Brain Stimulation: Basic, Translational, and Clinical Research in Neuromodulation. 2008;1(1):67.

45. Crowther L, Porzig K, Hadimani RL, Brauer H, Jiles DC. Realistically modeled transcranial magnetic stimulation coils for Lorentz force and stress calculations during MRI. IEEE Transactions on Magnetics. 2013;49(7):3426-9.

46. Rotenberg A, Muller PA, Vahabzadeh-Hagh AM, Navarro X, López-Vales R, Pascual-Leone A, et al. Lateralization of forelimb motor evoked potentials by transcranial magnetic stimulation in rats. Clinical Neurophysiology. 2010;121(1):104-8.

47. Vahabzadeh-Hagh AM, Muller PA, Pascual-Leone A, Jensen FE, Rotenberg A. Measures of cortical inhibition by paired-pulse transcranial magnetic stimulation in anesthetized rats. Journal of neurophysiology. 2010;105(2):615-24.

48. Tang AD, Bennett W, Hadrill C, Collins J, Fulopova B, Wills K, et al. Low intensity repetitive transcranial magnetic stimulation modulates skilled motor learning in adult mice. Scientific reports. 2018;8(1):4016.

49. Parthoens J, Verhaeghe J, Servaes S, Miranda A, Stroobants S, Staelens S. Performance Characterization of an Actively Cooled Repetitive Transcranial Magnetic Stimulation Coil for the Rat. Neuromodulation. 2016;19(5):459-68.

50. Deng Z-D, Lisanby SH, Peterchev AV. Electric field depth-focality tradeoff in transcranial magnetic stimulation: simulation comparison of 50 coil designs. Brain stimulation. 2013;6(1):1-13. 51. March SD, Stark SJ, Hadimani RL, Stiner DR, Senter MJ, Spoth KK, et al. Thermal and mechanical analysis of novel transcranial magnetic stimulation coil for mice. IEEE Transactions on Magnetics. 2014;50(9):1-5.

52. Minusa S, Osanai H, Tateno T. Micromagnetic Stimulation of the Mouse Auditory CortexIn VivoUsing an Implantable Solenoid System. IEEE Transactions on Biomedical Engineering. 2017;65(6):1301-10.

53. Minusa S, Muramatsu S, Osanai H, Tateno T. A multichannel magnetic stimulation system using submillimeter-sized coils: system development and experimental application to rodent brain in vivo. Journal of neural engineering. 2019;16(6):066014.

54. Huang Y-Z, Edwards MJ, Rounis E, Bhatia KP, Rothwell JC. Theta burst stimulation of the human motor cortex. Neuron. 2005;45(2):201-6.

55. Voss L, Jacobson G, Sleigh JW, Steyn-Ross A, Steyn-Ross M. Excitatory effects of gap junction blockers on cerebral cortex seizure-like activity in rats and mice. Epilepsia. 2009;50(8):1971-8.

56. Minusa S, Tateno T, editors. Developing an Implantable Micro Magnetic Stimulation System to Induce Neural Activity in Vivo. International Conference on Neural Information Processing; 2016: Springer.

57. Huang Y-Z, Lu M-K, Antal A, Classen J, Nitsche M, Ziemann U, et al. Plasticity induced by noninvasive transcranial brain stimulation: a position paper. Clinical Neurophysiology.

2017;128(11):2318-29.

58. Suppa A, Huang Y-Z, Funke K, Ridding M, Cheeran B, Di Lazzaro V, et al. Ten years of theta burst stimulation in humans: established knowledge, unknowns and prospects. Brain stimulation. 2016;9(3):323-35. 
59. Barry MD, Boddington L, Igelström KM, Gray JP, Shemmell J, Tseng KY, et al. Utility of intracerebral theta burst electrical stimulation to attenuate interhemispheric inhibition and to promote motor recovery after cortical injury in an animal model. Experimental neurology.

2014;261:258-66.

60. Sykes M, Makowiecki K, Rodger J. Long term delivery of pulsed magnetic fields does not alter visual discrimination learning or dendritic spine density in the mouse CA1 pyramidal or dentate gyrus neurons. F1000Research. 2013;2. 